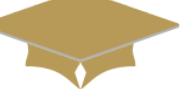

MEDRESEARCH

www.medresearch.in

\title{
Influence of Socio Demographic Factors on Anxiety among Third Year Student in Ahfad University
}

\author{
Mohamed Abasher Haj Ali S. ${ }^{*}$, Abdul-Moniem Mohammed El-Amin M. ${ }^{2}$, Azhari Mustafa Abdalla \\ $\mathrm{W}^{3}$
}

DOI: https://doi.org/10.17511/ijphr.2017.i1.01

1* Sana Mohamed Abasher Haj Ali, Assistant Professor, College of education, Psychology division, King Faisal University, Al Ahsa, Kingdom of Saudi Arabia.

2 Maha Abdul-Moniem Mohammed El-Amin, Assistant Professor, College of education, Psychology division, King Faisal University, Al Ahsa, Kingdom of Saudi Arabia.

3 Wafa Azhari Mustafa Abdalla, Counselor, Greative Centre for Rehabilitation, Doha, Qatar.

Introduction: Anxiety disorders are common in the general population around the world. They constitute a substantial proportion of the global burden of disease, and are projected to form the second most common cause of disability by 2020. The main objective of the study is to find out if third year student in Ahfad University, show some extent of anxiety and whether this is related to some social demographic factors. Methods: Beck anxiety Inventory (BAI) was used to measure anxiety level in randomly selected 182 students from different schools within the university campus. Statistical analysis was performed by using SPSS 16. Results: We found that the prevalence of anxiety was significant in third year students related to their age, economic and residential status and also related to their academic performances stating that students with low social demographic factors and with academic problems will experience higher levels of anxiety than those with good social demographic status and with no academic problems. Conclusion: From this study it is clear that the prevalence of anxiety was significant in third year students related to their age, economic and residential status and also related to their academic performances. We recommend more studies for further understanding the relation of anxiety with socio demographic factors.

Keywords: Anxiety, Socio demographic factors, University student, Sudan

Corresponding Author

Sana Mohamed Abasher Haj Ali, Assistant Professor, College of education, Psychology division, King Faisal University, Al Ahsa, Kingdom of Saudi Arabia. Email: shajali@kfu.edu.sa
How to Cite this Article

To Browse

Ali SM, El-Amin MA, Abdalla WA. Influence of Socio Demographic Factors on Anxiety among Third Year Student in Ahfad University. Public Health Rev Int J Public Health Res. 2017;4(1):1-8.

Available From

https://publichealth.medresearch.in/index.php/ijphr/ article/view/54

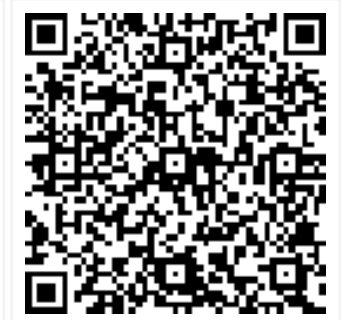

Manuscript Received 2016-11-18

Conflict of Interest No
Review Round 1 2016-11-26

Funding Nil

Review Round 2
2016-12-05
$\begin{gathered}\text { Ethical Approval } \\ \text { Yes }\end{gathered}$

Review Round 2 Yes
Review Round 3

Plagiarism X-checker $7 \%$
Accepted 2016-12-14

(c) 2017 by Sana Mohamed Abasher Haj Ali, Maha Abdul-Moniem Mohammed El-Amin, Wafa Azhari Mustafa Abdalla and Published by Siddharth Health Research and Social Welfare Society. This is an Open Access article licensed under a Creative Commons Attribution 4.0 International License https://creativecommons.org/licenses/by/4.0/ unported [CC BY 4.0].
Note 


\section{Introduction}

Anxiety disorders are common in the general population around the world. They constitute a substantial proportion of the global burden of disease, and are projected to form the second most common cause of disability by 2020 [1] and that kind of pressures on students has increased in recent years as a result of financial constraints, growing competitiveness, and heightened aspirations for achievement and material security.

Vulnerable students might need higher levels of support in order to achieve their potential [2]. Anxiety and its relation to socio-demographic have received widespread attention over the years $[3,4$, $5,6]$. Anxiety is a state of apprehension, uncertainty, and fear arising from the anticipation of a realistic or imagined threatening event, often impairing physical and psychological functioning [1].

People face anxiety every day. Youth experience certain emotional, behavioral, sexual, economic, academic, social and as well as efforts of discovering one's identity with psycho-social and sexual maturation. During this period, the mental health of university youth constitutes one of the important components of social health [7].

Evidence suggests that university students are vulnerable to mental health problems, has generated increased public concern in Western societies. University students are a special group of people that are enduring a critical transitory period in which they are going from adolescence to adulthood and that can be one of the most stressful times in a person's life [8]. Both retrospective and prospective researches have shown that most adulthood mental disorders begin in childhood and adolescence [9].

Moreover, previous studies suggest high rates of psychological morbidity, especially depression and anxiety, among university students all over the world [10]. In addition to demographic, social and clinical factors, such as sex and body mass index, and the role they play in the occurrence of symptoms of anxiety [11].

Our study's main concern is about the relationship between anxiety and socio-demographic factor among third year student in Ahfad University. Hence the study hypnotized that anxiety is high among third year Ahfad University students, and it is associated with socio-demographic factors such as ,
(Age, social support, marital status, economic status, residential status, educational level of parent). Also the study assumes that the level of anxiety is high among student who have academic problem, student living in hostel will have high anxiety than those living at home and finally student who have social support will have Low level of anxiety.

\section{Methodology}

Study design: It was a cross-sectional study, conducted among third year of Ahfad University for Women, which is a private University in Sudan offering both undergraduate and postgraduate degrees for females. It consists of 6 schools located in the same campus and have students coming from different tribes, cultural, and social background.

Study population and sample selection: The study target third year students from the six schools: Health Science, Psychology, Management, Medicine, Pharmacy and Reed (Rural Extension Educational and Development), during the academic year 2010/2011. Out of the 1220 students of six schools a random sample of 182 students were selected with the consent of their willingness to participate in the study, and were asked to fill the measurements used in this study.

Measurement- In this study we adopted Beck Anxiety Inventory (BAI) to measure anxiety level [12] with 21-item multiple-choice self-report inventory that measures the severity of the anxiety in adults and adolescents. BAI describe the emotional, physiological, and cognitive symptoms of anxiety but not depression, it can discriminate anxiety from depression. Although the age range for the measure is from 17 to 80 , it has been used in peer-reviewed studies with younger adolescents aged 12 and older. Each of the items on the BAI is a simple description of a symptom of anxiety in one of its four expressed aspects: (1) subjective (e.g., "unable to relax"), (2) neurophysiologic (e.g., "numbness or tingling"), (3) autonomic (e.g., "feeling hot") or (4) panic-related (e.g., "fear of losing control"). The questionnaire is administered orally for sight-impaired individuals. The interpretation is done professionals with appropriate clinical training and experience. The respondent is asked to rate how much he or she has been bothered by each symptom a 4-point scale ranging from 0 to 3 . The items are summed to obtain a total score that can range from 0 to 63 . 
Statistical Analysis: Correlation coefficient, was used to assess the relationship between sociodemographic variables and anxiety scale by using SPSS 16, T-test to reveal the mean value of anxiety and tukey test to find the differences in anxiety among third year students in Ahfad University in relation to social support.

Ethical: The study was approved by the Director of Ahfad University and the Institutional ethical committee.
Participants were assured confidentiality of their responses and informed verbal and written consent before their participation in the study.

\section{Results}

Results in Table (1) shows that T-Test revealed that the mean value of anxiety among third year students in this study was $(21.78 \pm 12.78)$ with probability value of $(0.001)$ at significant level (0.05).

Table-1: One sample $T$ test to know the level of anxiety among third year students in Ahfad University

\begin{tabular}{|l|l|l|l|l|c|l|l|l|}
\hline & No of cases & No of phrases & Theoretical mean & Mean & SD & T Value & P value & Conclusion \\
\hline Level of anxiety & 183 & 21 & 31.5 & 21.78 & \pm 12.87 & 22.80 & 0.001 & The level of anxiety is significantly Moderate* \\
\hline
\end{tabular}

$* \mathrm{P} \leq 0.05$ (significantly moderate-to-severe level of anxiety). Data was presented as mean \pm SD. The levels of anxiety was significantly moderate. $\mathrm{P}=0.001$.

Fig-1: Range of anxiety among third year students in Ahfad University

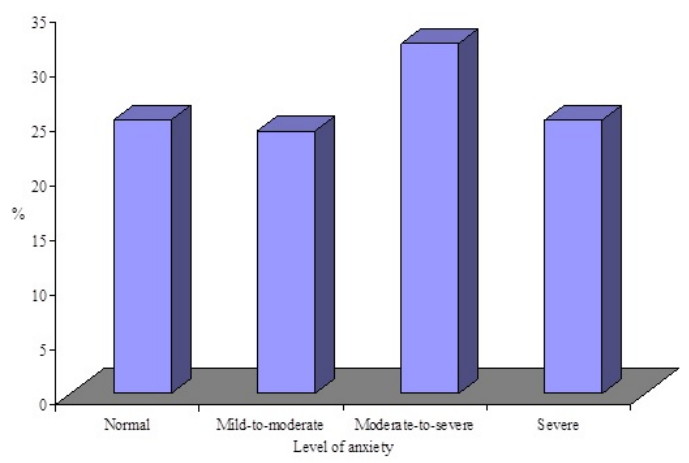

Table 1 figure 1 shows that there is moderate-tosevere anxiety among the third year students which was significantly moderate at $\mathrm{P}=0.001$, while Mean is 21.78 and SD is \pm 12.87 .
Table-2: Pearson's coefficient factor test to know the relationship between anxiety among third year students in Ahfad University and some demographic variables

\begin{tabular}{|l|l|l|l|}
\hline Variables & $\begin{array}{l}\text { Pearson Coefficient factor of } \\
\text { the variable with anxiety }\end{array}$ & $\begin{array}{c}\mathbf{P} \\
\text { value }\end{array}$ & \multicolumn{1}{|c|}{ Conclusion } \\
\hline Age & 0.22 & 0.01 & $\begin{array}{l}\text { There is significant } \\
\text { correlation* }\end{array}$ \\
\hline $\begin{array}{l}\text { Marital } \\
\text { status }\end{array}$ & 0.03 & 0.74 & $\begin{array}{l}\text { There is no } \\
\text { significant } \\
\text { correlation** }\end{array}$ \\
\hline $\begin{array}{l}\text { Education } \\
\text { of parents }\end{array}$ & 0.06 & 0.42 & $\begin{array}{l}\text { There is no } \\
\text { significant } \\
\text { correlation** }\end{array}$ \\
\hline
\end{tabular}

* $\mathrm{P}$ value $\leq 0.05$ Significant relationship between the two variables)

** $\mathrm{P}$ value $\leq 0.05$ (No Significant relationship between the two variable

Table 2 shows the relationship between the level of anxiety among study group and their ages, marital status, and educational level of the parents.

Table 3: Multiple comparisons (Tukey) Test to know differences in anxiety among third year students in Ahfad University in relation to social support

\begin{tabular}{|c|c|c|c|c|c|}
\hline Social support $* *$ & \multicolumn{2}{|c|}{ Diff. } & $\begin{array}{l}\text { Standard } \\
\text { error }\end{array}$ & $\begin{array}{l}\text { Significance } \\
\text { level }\end{array}$ & Conclusion \\
\hline \multirow[t]{2}{*}{ No support } & Little & -0.38 & 2.59 & $0.99 *$ & \multirow{6}{*}{$\begin{array}{l}\text { There no is significant differences in anxiety among the study subjects } \\
\text { attributed to social support }\end{array}$} \\
\hline & Much & -1.37 & 3.44 & $0.92 *$ & \\
\hline \multirow[t]{2}{*}{ Little support } & No support & 0.38 & 2.59 & 0.99* & \\
\hline & Much & -0.99 & 2.79 & $0.93 *$ & \\
\hline \multirow[t]{2}{*}{ Much support } & No support & 1.37 & 3.44 & $0.92 *$ & \\
\hline & Little & 0.99 & 2.79 & $0.93 *$ & \\
\hline
\end{tabular}


* Differences are significant at 0.05 level $(P \leq 0.05)$

** Dependent variable $=$ degree of anxiety on Beck Inventory Scale. Independent variable $=$ social support.

For the relationship between age and level of anxiety, Pearson coefficient factor value was $(0.22)$ with probability value of $(0.01)$ at significant level of (0.05). For marital status, Pearson coefficient factor value was (0.03) with probability value of $(0.74)$ at significant value (0.05). For parents' educational level, Pearson coefficient factor value was (0.06) with probability value of $(0.42)$ at significant value (0.05).
Accordingly, there is strong relationship between the level of anxiety among third year students in Ahfad University and their ages $(P \leq 0.05)$, while no relationship existed between anxiety marital status and educational level of parents $(P>0.05)$.

Fig-3: Anxiety among third year students in Ahfad University in relation to social support

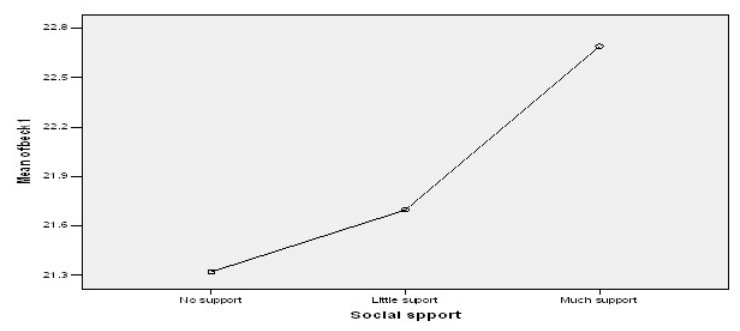

Table-4: Multiple comparisons (Tukey) Test to know differences in anxiety among third year students in Ahfad University in relation to economic condition

\begin{tabular}{|c|c|c|c|c|c|}
\hline Money given ** & \multicolumn{2}{|l|}{ Diff. } & Standard error & Significance level & Conclusion \\
\hline \multirow[t]{2}{*}{ Not enough } & Fairly Enough & 2.03 & 2.26 & $0.02 *$ & \multirow[t]{6}{*}{ There is a significant difference on the side of not enough money } \\
\hline & Enough & 3.12 & 2.62 & $0.01 *$ & \\
\hline \multirow[t]{2}{*}{ Fairly enough } & Not enough & -2.03 & 2.26 & $0.02 *$ & \\
\hline & Enough & 1.09 & 2.37 & $0.04 *$ & \\
\hline \multirow[t]{2}{*}{ Enough } & Not enough & -3.12 & 2.62 & $0.01 *$ & \\
\hline & Fairly enough & -1.09 & 2.37 & $0.04 *$ & \\
\hline
\end{tabular}

* Differences are significant at 0.05 level $(P \leq 0.05)$

** Dependent variable $=$ degree of anxiety on Beck Inventory Scale. Independent variable = economic condition

Table 3 and figure 3 show the differences between the level of anxiety among the study group and social support.

The mean differences between the three social support categories in anxiety were $(-0.38)$ between those have no support and those have little support, $(-1.37)$ between those have no support and those have much support, and (-0.99) between those have little support and those have much support. The mean values of anxiety were $21.3,21.6$, and
22.8 for students who have no social support, little social support and much social support respectively. The probability values were greater than (0.05).

Table 4 shows the differences between the level of anxiety among the study group and economic conditions. The main differences between the categories of economic conditions in anxiety were (2.03) between those of low economic condition and those of medium level, (3.12) between those of low economic condition and those of high level, and (1.09) between those of medium economic condition and those of high level. The mean values of anxiety were $23.5,21.47$, and 20.38 for students with low, medium and high economic status respectively. The probability values were less than $(0.05)$.

Table-5: Multiple comparisons (Tukey) Test to know differences in anxiety among third year students in Ahfad University in relation to residential status

\begin{tabular}{|c|l|l|l|l|l|}
\hline Residential status $* *$ & \multicolumn{2}{|c|}{ Diff. } & \multicolumn{1}{|c|}{ Standard error } & Significance level & \multicolumn{1}{c|}{ Conclusion } \\
\hline \multirow{2}{*}{ Relatives } & Other & 1.32 & 2.73 & $0.04 *$ & There is a significant differences on the side of those \\
\cline { 2 - 5 } & Family & 7.58 & 4.19 & $0.01 *$ & \\
& Hostel & -3.52 & 5.84 & $0.01 *$ & \\
\hline
\end{tabular}




\begin{tabular}{|l|l|l|l|l|}
\hline Other & Relatives & -1.32 & 2.73 & $0.04^{*}$ \\
\cline { 2 - 5 } & Family & 9.26 & 4.77 & $0.02^{*}$ \\
& Hostel & -4.83 & 6.26 & $0.003^{*}$ \\
\hline Family & Relatives & -7.58 & 4.19 & $0.01^{*}$ \\
\cline { 2 - 5 } & Other & -6.26 & 4.77 & $0.02^{*}$ \\
& Hostel & -11.10 & 7.03 & $0.002^{*}$ \\
\hline Hostel & Relatives & 3.51 & 5.84 & $0.01^{*}$ \\
& Other & 4.83 & 6.26 & $0.003^{*}$ \\
& Family & 11.10 & 7.03 & $0.002^{*}$ \\
\hline
\end{tabular}

* Differences are significant at 0.05 level $(P \leq 0.05)$

** Dependent variable $=$ degree of anxiety on Beck Inventory Scale. Independent variable $=$ residential status

Fig-5: Level of anxiety among third year students in relation to residential status

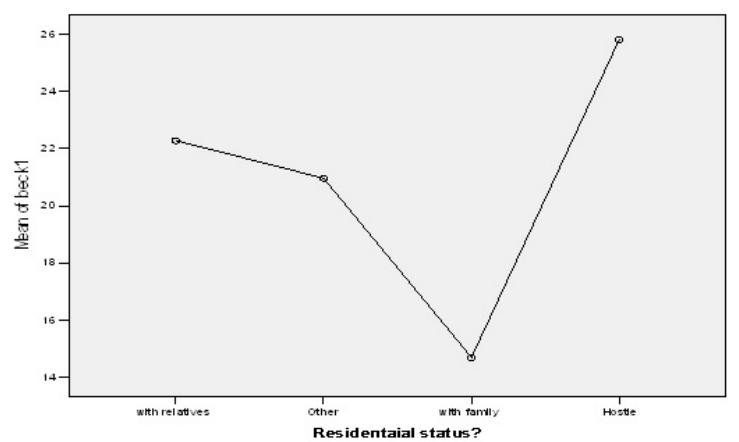

Table 5 and Figure 5 show the differences between the level of anxiety among the study group and residential status.

The mean differences between the categories of residential status in anxiety were (1.32) between those living with relatives and those with other, (7.58) between those living with relatives and those with family, (-3.52) between those living with relatives and those with living in hostel, (6.26) between those living with others and those with family and $(-11.10)$ between those living with family and those with in hostel,.

The mean values of anxiety were 22.28, 20.96, 14.70 and 25.80 for students living with relatives, others, family and hostel respectively. The probability values were less than (0.05).

Table-6: Independent samples $T$ test to know differences in anxiety among third year students in Ahfad University due to their academic performance

\begin{tabular}{|l|l|l|l|l|l|l|}
\hline \multicolumn{1}{|c|}{$\begin{array}{c}\text { Problems in } \\
\text { academic } \\
\text { performance }\end{array}$} & No of & Mean & SD & T value & P value & \\
\cline { 1 - 4 } Yes & 77 & 24.10 & \pm 13.61 & 10.14 & 0.047 & There is a significant difference in the level of anxiety among the third years \\
No & 106 & 20.08 & \pm 12.07 & & & students in favor of students with academic problems * \\
\hline
\end{tabular}

* $\mathrm{P}$ vale $\leq 0.05$ significant different

Fig-6: Anxiety among third year students in relation to academic performance

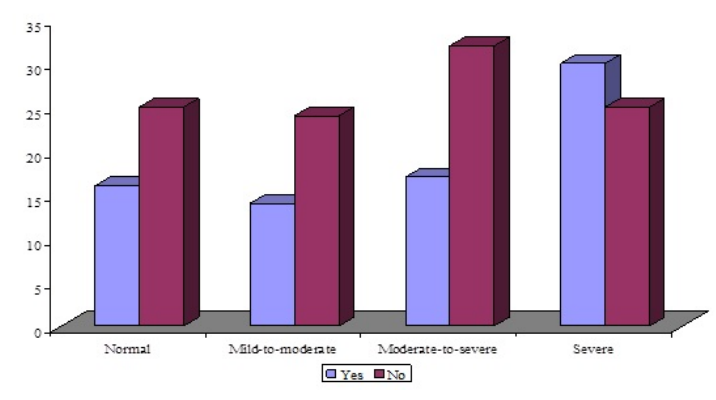

As shown in Table (6) and Figure (6), Independent variables $t$ test shows that the mean degree among third year students on anxiety scale was (24.10) with standard deviation of $( \pm 13.61)$ for students who have academic problems, while for students who have no academic problems the mean degree on the scale was (20.08) with standard deviation of $( \pm 12.07)$. The calculated $T$ value was $(10.14)$ with probability value of (0.047) at significant level (0.05). Accordingly, there is significant difference in the level of anxiety among third year students in Ahfad University attributed to academic performance. 


\section{Discussion}

The main aim of this study is know the extent of anxiety among third year students in Ahfad University for Women in relation to some demographic factors and academic performance. The findings revealed that there is moderate-tosevere anxiety among the third year students.

This finding could be explained by the fact that the study group now in milled stage of study course and to some extent became familiar with stressors and other factors associated with increased anxiety state among university students.

These results agreed with early studies which found that prevalence of anxiety and depression in students of 4th year, 3rd year, 2nd year and 1st year was $49 \%, 47 \%, 73 \%$ and $66 \%$ respectively. It was significantly higher in 1st year and 2nd year, as compared to $3 r d$ and 4 th year $(p<0.05)$.

Some demographic characteristics were tested in relation to anxiety among third year students. The findings showed that there is strong relationship between the level of anxiety among third year students in Ahfad University and their ages ( $P \leq$ $0.05)$, while no relationship existed between anxiety marital status and educational level of parents ( $P$ > 0.05).

This result disagreed with earlier studies, who found that not all comparisons between age groups with the same sex, however, were significant; and there was no significant correlations for anxiety with both family size and number of siblings, but significant and positive correlations for anxiety with birth order were found for boys $(r=.10, p<.01)$ and girls $(r=.06, p<.05)$.

Concerning social support and its relation to anxiety among third year students, the findings showed that there are no significant differences among third students in anxiety with regard to social support. However, previous studies confirmed that there is strong relation between anxiety and social support. Results also revealed that there are significant differences among third year students in anxiety with regard to economic status.

It is clear that economic condition one of the most common factors that affect student's mode and psychological well being and thus it is strongly associated with development of anxiety state. These results agreed with earlier studies, which stated that controlling for gender and family socioeconomic
Status, the following characteristics predict both state and trait anxiety: the status of family relationships, difficulty understanding lectures, difficulty adapting to university life, having to solve problems independently, a vision of self-sufficiency in problem solving, negative life experience, and satisfaction with their department of study.

Moreover, results showed that there are significant differences among third year students in anxiety with regard to residential status, in that living with family or relative or in hostel for students is different. Those living with families experienced low levels of anxiety than those living with relatives or in hostels. This agreed with earlier studies, which found that students living in university dormitories were significantly more depressed and anxious than those living at home.

Also it has been found that environmental and social circumstances play a major role in the onset of stress-related diseases. Results showed that there is a significant difference in the level of anxiety among third year students in Ahfad University regarding the academic performance in favor of students with academic problems. Student distress may effect progress of their carrier, and adversely affect patient care quality, patient security and dedication.

\section{Conclusion}

From this study it is clear that the prevalence of

Anxiety was significant in third year students related to their age, economic and residential status and also related to their academic performances stating that students with low social demographic factors and with academic problems will experience higher levels of anxiety than those with good social demographic status and with no academic problems. Previous studies also had confirmed these findings.

\section{Reference}

01. Bastos J C, Mohallem A G, Guilhermina O F. Anxiety and depression in Nursing students during Oncology internship. Einstein. 2008;6;712.

[Crossref]

02. Royal College of Psychiatrists. The mental health of students in higher education. Council Report CR112, London. 2003.

Available from: [Article] [Crossref] 
03. Bayram N, Bilgel N. The prevalence and sociodemographic correlations of depression, anxiety and stress among a group of university students. Soc Psychiatry Psychiatr Epidemiol. 2008 Aug;43(8)667-72.

doi: $\quad 10.1007 / \mathrm{s} 00127-008-0345-x \quad$ [Crossref]

04. Roupa Z, Koulouri A, Sotiropoulou P, Makrinika E, Marneras X, Lahana I, Gourni M. Anxiety and depression in patients with Type 2 Diabetes Mellitus, depending on sex and body mass index. Health Science Journal. 2009;32(3)3240.

[Crossref]

05. Michael B. DSM Consultant to the American Psychiatric Institute for Research and Education (APIRE), a subsidiary of the American Psychiatric Association. Comorbidity of Depression and Generalized Anxiety Disorder. 2007.

[Crossref]

06. Gul Arslan, Dr Unal Ayranci, Alaettin Unsal, and Didem Arslantas. Prevalence of depression, its correlates among students, and its effect on health-related quality of life in a Turkish university. Ups J Med Sci. 2009 Sep;114(3)170177.

[Crossref]

07. Adewuya AO, Ola BA, Aloba OO, Mapayi BM, Oginni OO. Depression amongst Nigerian university students, Prevalence and sociodemographic correlates. Soc Psychiatry Psychiatr Epidemiol. 2006 Aug;41(8)674-8. [Crossref]

08. J L Buchanan. Prevention of depression in the college student Population- a review of the literature. Arch Psychiatric Nurs. 26;1(2012)2142.

[Crossref]
09. RC Kessler, GP Amminger, S Aguilar-Gaxiola, J Alonso, S Lee, TB Ustun. Age of onset of mental disorders: a review of recent literature. Curr Opin Psych. 20(2007)359-364.

[Crossref]

10. William Matteson. Missing The Diagnosis- The Hidden Medical Causes of Mental Disorders. Courses for Mental Health Professionals. 2010. [Crossref]

11. Khan $H$, S K Ahmed Itrat, Khan A, Kamal $M$, Khan MA, Khalid $R$, et al. Prevalence and demographics of anxiety disorders- a snapshot from a community health centre in Pakistan. Ann Gen Psychiatry. 2007;6;30.

[Crossref]

12. Aaron T. Beck. Beck Anxiety Inventory. 1996. [Crossref]

13. Dyrbye LN, Thomas MR, Shanafelt TD. Systematic review of depression, anxiety, and other indicators of psychological distress among US and Canadian medical students. Acad Med. 2006 Apr;81(4)354-73.

[Crossref]

14. Shanafelt TD, Bradley KA, Wipf JE, Back AL. Burnout and self-reported patient care in an internal medicine residency program. Ann Intern Med. 2002; Mar 5;136(5)358-67.

[Crossref]

15. Mareiniss DP. Decreasing GME training stress to foster residents' professionalism. Acad Med. 2004;Sep;79(9)825-3.

[Crossref] 